\title{
«MASWITI SAMADYERA MU PEPALA» (LOS CARAMELOS NO SE COMEN ENVUELTOS)
}

\author{
Palmira Alcalde \\ Máster en Antropología Médica y Salud Global \\ Universitat Rovira i Virgili \\ plmrlcld@gmail.com
}

RESUMEN: Desde que en 1985 se detectó el primer caso oficial de sida, el VIH se ha convertido en el principal problema de salud en Malawi y en la primera causa de mortalidad entre la población. Aunque las políticas de prevención del contagio y el acceso a los tratamientos antirretrovirales han conseguido reducir la mortalidad, la prevalencia continúa siendo alta y está especialmente feminizada. En una sociedad en la que las relaciones de poder y las desigualdades de género se vinculan estrechamente con el contagio del VIH, las mujeres, dependientes económica y socialmente del hombre, en la mayoría de los casos, se encuentran en una situación de mayor vulnerabilidad social y de mayor riesgo de contagio.

A partir del análisis de entrevistas realizadas a mujeres seropositivas y de algunos de los conceptos emic presentes en las narrativas, se estudian las causas que más inciden en esta feminización del VIH. La investigación demuestra que una sociedad fuertemente patriarcal, la pobreza y el escaso control de la mujer en la toma de decisiones como son el acceso a la planificación familiar, una eficaz educación sexual, la elección de marido o la de tener hijos o no, así como la de rechazar relaciones sexuales no seguras, aumentan el riesgo de contagio del VIH.

PALABRAS CLAVE: VIH; sexualidad; mujer; condón; estigma; cultura. 
ABSTRACT: Since the detection of the first official case of AIDS in Malawi in 1985, HIV has become the main health problem in the country and the leading cause of mortality among the population. Although policies aimed at preventing infection and providing access to antiretroviral treatments have significantly reduced mortality, the prevalence of the among the population remains high, particularly among women. In a society in which power relations and gender inequalities are closely linked to the spread of HIV, women are at particularly disadvantaged because in most cases they depend financially and socially on men. This places them in a situation of greater social vulnerability and at greater risk of contagion.

Based on the analysis of interviews with seropositive women, and some emic concepts present in their narratives, the present article analyses the causes that most affect this feminization of HIV. Research shows that the risk of infection with HIV is increased by a strongly patriarchal society, poverty, unsafe sex, women's limited control in decision-making, their lack of access to family planning and effective sex education, the fact that they do not have the right to choose their husbands or whether to have children or not.

KEYWORDS: HIV; sexuality; woman; condoms; stigma culture. 


\section{Introducción}

Malawi, situado en el sureste de África, está dividido administrativamente en tres regiones: sur, centro y norte, y su población, de 18 millones de personas según el Banco Mundial (BM, 2016), la conforman etnias distintas: chewa, ngoni, tumbuka, yao, lomwe... El idioma nacional es el chichewa y el inglés, el que dominan las élites, el oficial, aunque la diversidad de tribus conlleva variedad de lenguas propias de cada etnia. La familia como unidad social ha experimentado cambios sustanciales en la sociedad malawiana pero todavía existen dos tipos de matrimonio «tradicional $»^{1}$, como lo definen Chimbiri (2007) y Walther (2017), algo relevante porque sus costumbres, en las relaciones de género y rituales vinculados con las prácticas sexuales, difieren; no obstante, ambos son fuertemente patriarcales y el poder económico y social recae, de una manera u otra, sobre los hombres de la familia.

Malawi es pobre, el 50,7\% de la población vive bajo el umbral de la pobreza según el Alto Comisionado de las Naciones Unidas para los Refugiados (ACNUR, 2017), y su economía, basada en la agricultura de subsistencia, representa el $30 \%$ de su producto interior bruto, empleando a casi el $80 \%$ de la población activa, sobre todo jóvenes ${ }^{2}$ y mujeres; el cultivo del maíz es el alimento básico y sobre el que recae su seguridad alimentaria. La poca mecanización y la dependencia de la climatología hacen sus cosechas muy vulnerables, con la amenaza constante de hambrunas periódicas, como las de los años 2002, la peor de la época moderna (McCracken, 2012), y 2005, que llevaron al país a una emergencia alimentaria y causaron gran mortandad ${ }^{3}$.

I En Malawi coexisten dos sistemas de matrimonio que reposan en dos sistemas de filiación: matrilineal/matrilocal predominante en las regiones sur y centro del país, mientras que en la región norte es más común el sistema patrilineal/patrilocal. En el sistema matrilineal la adscripción del individuo y la herencia vienen dadas por la línea materna, siendo el hermano de la madre quien dispone y controla las propiedades y recursos heredados, incluida la propiedad de la tierra. En el sistema patrilocal, al contrario, la adscripción es por la vía paterna; de padre a hijos u otros varones de la familia, y la poligamia y el levirato son prácticas bastante comunes. La mujer debe trasladarse a vivir a la localidad del marido, que paga un precio por la novia: lobola.

2 La edad media de la población se sitúa en 17,4 años (WWP, World Population Prospect, 2015).

3 Mercedes, misionera de la comunidad de María Mediadora, me relató los estragos que la hambruna de esos años, especialmente la del 2002, produjo en el país. La noticia fue recogida en di- 
Desde su independencia en 1964, Malawi depende de la ayuda internacional. Entre 2007 y 2009, la ayuda externa supuso el 40\% del presupuesto nacional; el Reino Unido, Japón, el Fondo Monetario Internacional y el BM aportaron, en 2008, casi un billón de dólares en ayudas al desarrollo (Myroniuk, 2011, citado en Page, 2014), y en 2017, los préstamos de la Asociación Internacional de Fomento ascendieron a 421.400 millones (BM, 2018). A pesar de las ayudas la economía continúa siendo una asignatura pendiente.

La desconfianza de los inversores extranjeros se basa en la falta de transparencia política en las inversiones, las deficientes infraestructuras para el transporte de mercancías y la pobre gestión medioambiental (Record, Kumar y Kandoole, 2018). Los cortes de electricidad continuos ${ }^{4}$ son un grave problema para la industria y la población, y una carga económica para Malawi porque la falta de generación de electricidad obliga al Gobierno a comprarla fuera y a los individuos, a utilizar la madera y el carbón cuando esta falta, aumentando así la deforestación del país.

En 2013, realizando trabajo de campo para mi TFG, tomé conciencia de la dimensión del problema del VIH/sida para el país y para los individuos, especialmente para las mujeres; porque una característica de la epidemia es su feminización. De los 36,7 millones de personas que en 2016 vivían con el VIH en el mundo, un millón eran malawianas; de ellas, 590.000 mujeres mayores de 15 años, con una prevalencia estimada del $11,7 \%$ entre las mujeres de 15-49 años versus un 7,4\% entre los hombres del mismo rango de edad (UNAIDS, 2017).

La sociedad malawiana es todavía muy tradicional ${ }^{5}$, especialmente en las zonas rurales en las que vive el 83,4\% de la población (Food and Agriculture Organization, FAO, 2017), exhibiendo las desigualdades sociales y de género, relacionadas con el contagio del VIH, transmitido principal-

\footnotetext{
versos medios como BBC. Mundo News digital: <http://new.bbc.co.uk/hi/spanish/news/newsid 1950000/1950772.stm>.

4 Durante mi estancia los cortes de luz eran diarios, sin preaviso, y podían darse mañana o tarde.

5 Para evitar la problemática que el término «tradicional» implica en antropología, quiero aclarar que cuando menciono «sociedad tradicional» me refiero a una sociedad que todavía mantiene costumbres muy arraigadas, anteriores a la colonización y cristianización del país.
} 
mente por contacto heterosexual. La homosexualidad es ilegal en el país y está castigada con la prisión (Otosson, 2017).

La dependencia económica y social del hombre resta capacidad de agencia a la mujer para negociar conductas de riesgo en las relaciones sexuales: obligarle a utilizar preservativo, negarse a la relación sexual o evitar la poligamia del marido (practicada por el 18\% de la población), según el sondeo Malawi Demographic and Health Survey (MDHS, 2017), la hace más vulnerable al riesgo del contagio del VIH, como afirman algunas informantes:

En Malawi, los hombres tienen más poder [...] si un hombre decide no usar condón pienso que la mujer no puede rechazarlo. Tiene miedo de perder la amistad y las fuentes económicas (Analy, médico).

Nuestras prácticas culturales contribuyen [...] en nuestra cultura el hombre es el héroe de la familia, quien toma las decisiones [...] la mayoría de las mujeres no estamos empoderadas. Necesitamos empoderarnos, tomar nuestras propias decisiones, no solo la imposición del marido (Isabel, responsable del Departamento VCT).

La razón por la que muchas personas seropositivas no revelan su estatus es el miedo al estigma y a la discriminación, consecuencia de los discursos moralizadores de las élites políticas, sociales y religiosas, que determinan las políticas sobre el VIH/sida. Las élites locales a las que se refiere este trabajo no son grupos intrínsecamente políticos y están repartidas entre las diferentes esferas del poder, pero en un país en desarrollo, el círculo religioso es el que más contacto tiene con las instituciones extranjeras, especialmente en los sectores de sanidad y educación. El dominio del inglés, símbolo de modernización y elitismo de quienes lo utilizan como herramienta de trabajo (Matiki, 2001), una formación académica que, como mínimo, alcanza la enseñanza secundaria y el hecho de que todos trabajan, de una forma u otra, en el campo del VIH, ya sea diseñando las políticas de prevención o implementándolas, en colaboración con organizaciones internacionales, u ocupando cargos en la Administración, son rasgos comunes.

Esta investigación, en línea con el paradigma interpretativista de Geertz (1973), cuyos métodos de investigación se centran, principalmente, 
en la observación participante, la etnografía, la fenomenología y el análisis del discurso, pretende dar respuesta a preguntas sobre la vinculación entre la construcción «oficial» del discurso del VIH/sida y la percepción de este por parte de los individuos, así como los factores que subyacen en su feminización. El trabajo de campo se llevó a cabo en 2017, durante los meses de septiembre y octubre, en los hospitales Likuni Mission, Mlale y Home Based Clinic, en un radio de $10-30 \mathrm{~km}$ de la capital, Lilongwe. Los hospitales de Likuni y Mlale forman parte de la organización Christian Health Association of Malawi, creada en 1966 bajo los principios religiosos de proveer soporte técnico y administrativo para mejorar la salud de sus miembros en todo el país. Esta institución es el segundo proveedor más importante en servicios de salud del país, el 37\%, y forma al 80\% de sus profesionales, complementando de forma sustancial la asistencia sanitaria pública (Likuni Mission Hospital, 2016).

Se realizaron entrevistas en profundidad, a treinta mujeres seropositivas y a otros actores sociales, médicos, enfermeras y a personas no seropositivas, así como a jóvenes de ambos sexos con los que, de manera distendida y coloquial, se conversó sobre el tema. También se recabó información en la prensa local ${ }^{6}$, lo que permite tener una visión panorámica de los problemas que durante el tiempo que duró la investigación fueron noticia; los cortes de suministro eléctrico diarios, los embarazos adolescentes, el estado de excepción en la ciudad de Blantyre por algunos casos de vampirismo, blood-suckers; los matrimonios precoces, etc.

El objetivo de las preguntas era conocer quién les había comunicado que eran seropositivas; cómo lo percibieron; a qué personas revelaron su estado; su conocimiento del VIH/sida y cómo previnieron el contagio, en el caso de mantener relaciones sexuales.

\section{Efectos de la colonización y de la globalización}

El colonialismo constituyó la unión estratégica de ideas, instituciones y formas de dominación, ya en nombre de Dios, la ciencia y el capital, ya bajo la premisa de la evangelización, la civilización o el comercio, para

6 Anexo con noticias de prensa local sobre estos temas. 
instaurar el «orden», un modo de vida social y un establecimiento de la «verdad», principales rasgos de una particular visión de la razón, el progreso y la libertad: estas ideas, propias de la Ilustración, impregnaban la mentalidad de los imperios europeos. Un «nuevo orden» que, irónicamente, ha llevado al «desorden» político, económico y social de muchos de los nuevos estados poscoloniales (DelVecchio et al., 2008).

Este apartado se centrará, principalmente, en las consecuencias que la colonización inglesa tuvo para Malawi, en aspectos directamente vinculados con la epidemia; en especial en la relevancia de la cristianización del país como factor identitario de las élites postcoloniales.

Los primeros misioneros, protestantes y católicos, llegaron a principios del siglo xx con la voluntad de hacer de la evangelización una obra civilizadora según el modelo occidental. Sus aportaciones acercaron a los individuos al mundo moderno y contribuyeron al desarrollo de la agricultura, las artes, y a las virtudes de las personas, de acuerdo con la doctrina cristiana, aunque, según Belda (1975), imbuidos en los prejuicios de la época, la mayoría de los religiosos no se esforzaron en comprender la mentalidad de los individuos. «Lo cierto es que los cristianos también hemos manipulado a personas y a grupos sociales queriendo ser fieles al Evangelio [...] con la justificación de diversas formas de coacción ejercitada contra la conciencia ciudadana (recepción de sacramentos sin fe personal, enseñanza religiosa ajena a las propias convicciones, evangelización proselitista)» (Belda, 1975: 260).

Las ideas del pecado y la salvación comportaron cambios sustanciales en la percepción de la sexualidad y las prácticas sexuales tradicionales, la estructura familiar y las relaciones de género en la sociedad malawiana. Unos cambios que, según Bochow y Van Dijk (2012), lejos de reducir las desigualdades entre hombres y mujeres, perpetúan los roles de género y acentúan la dominación masculina.

Con la noción del pecado el cristianismo introdujo también la concepción moral victoriana de la sociedad burguesa inglesa que, en plena Revolución industrial, ve peligrar sus intereses por la degeneración de la conducta sexual de las clases trabajadoras. Es entonces cuando el sexo pasa de ser algo público a algo secreto, reducido al matrimonio, quedan- 
do la sexualidad confinada a su función reproductora y controlada por el poder, generando con sus discursos un nuevo sistema de relaciones en las que la voluntad del individuo no cuenta (Foucault, 1998).

La ideología colonial desarrolló una conciencia dual que dio lugar a nuevas subjetividades e «identidades híbridas» de los individuos y propició la emergencia de unas élites en los Estados poscoloniales africanos más afines con las élites occidentales que con «su propia gente», sosteniéndolas en su objetivo por sobrevivir (Galtung, 1971). Para legitimar su existencia dentro de los contextos occidentales se convierten al cristianismo, alejándose de los individuos que se mantienen fieles a costumbres: practicar la medicina tradicional, sing'ganga (herbolarios), rituales de brujería ${ }^{7}$, etc., y a los que ven como atrasados. Los herbolarios tienen todavía un peso importante entre muchos malawianos que creen en los poderes curativos de plantas y animales, no solo a nivel terapéutico, también para tener buena suerte o protegerse contra la brujería, en los ritos de paso, especialmente de iniciación y funerales (Morris, 2011; MacCracken, 2012).

A pesar del intento de la Iglesia colonial de erradicar la idolatría, prohibiendo y desarticulando cosmovisiones y saberes populares para mantener su monopolio sobre lo espiritual (Sanchiz, 1995), las prácticas tradicionales continúan realizándose en todo el país, especialmente en las áreas rurales. Algunas de estas prácticas son los rituales de iniciación femenina; kuchotsa fumbi en las que hombres adultos fisi ${ }^{8}$ tienen sexo con las recién iniciadas, el pago de la novia, lobola, el levirato, chokolo, que obliga a la mujer viuda a casarse con el hermano del difunto marido, o la poligamia, mitala. Algunas de estas prácticas, que en el contexto tra-

7 Los albinos, por ejemplo, son perseguidos y asesinados por la creencia de las propiedades curativas de sus órganos.

8 Fisi significa hiena y en chichewa; aparte de nombrar al animal, tiene dos significados. El primero se refiere al hombre elegido por el líder del pueblo para tener sexo con las chicas jóvenes después del ritual de iniciación. El hombre que practica sexo individuamente con cada una de las chicas, normalmente sin protección, lo hace durante la noche y no es identificado. El segundo significado se refiere a la contratación de los servicios de un hombre para tener sexo con una mujer que no puede concebir, lo que hace que este acuerdo sea secreto. El 18 noviembre de 2016 el artículo de la BBC tuvo gran repercusión internacional: un hombre, infectado de VIH, reconoció haber tenido sexo con más de 100 mujeres y chicas sin protección. Fue juzgado y condenado. Disponible en: <http://www.bbc. $\mathrm{com} /$ news/world-africa-38028065>. 
dicional tenían como objetivo ofrecer seguridad económica a la mujer, empezaron a ser identificadas como un factor de riesgo con el evento del $\mathrm{VIH} /$ sida.

Las Iglesias cristianas, protestantes y católicas centran sus mensajes de prevención de las enfermedades de transmisión sexual y el VIH en la fidelidad y la abstinencia, condenando la utilización de condones (Rankin et alii, 2016), aunque la realidad hace que este mensaje parezca ingenuo, pues la mayoría de las esposas fieles son infectadas por sus maridos. El informe de 1992 de la Organización Naciones Unidas, citado en Farmer (2000: 191), «[...] para la mayoría de las mujeres, el principal factor de riesgo para una infección de VIH es estar casada», es totalmente vigente para las mujeres de Malawi, como se desprende de las entrevistas realizadas a mujeres casadas o con pareja estable.

Si la colonización y la cristianización moldearon las estructuras, organización y prácticas de la sociedad malawiana, la globalización, ya como estado independiente, al contrario de lo que la filosofía capitalista afirmaba, no trajo mejoras sustanciales al país ni a los individuos, tanto en el terreno económico como en el social, especialmente para las mujeres. El libre mercado, junto con las políticas de privatización y desregularización, acentuó la desigualdad de géneros, reforzando los estereotipos de la superioridad «natural» del hombre y la inferioridad de la mujer (Van den Borne, 2005). El despido masivo de trabajadores no solo ha obligado a las mujeres del África tradicional a hacer frente al impagado trabajo doméstico y el cuidado de ancianos y niños, también han tenido que ser el sostén familiar cuando los maridos emigraban (Madunagu, 2001). Algunas de ellas recurren al sexo transaccional para la subsistencia, aumentando el riesgo de contraer el VIH, aunque no siempre es la necesidad económica imperiosa; el placer y el deseo, así como poder disponer de artículos que para ellas son un lujo (jabones o cremas o vestidos), también abocan al sexo transaccional (Schatz, 2005; Tawfik y Watkins, 2007). 


\section{Sexualidad y VIH/sida}

En el África tradicional la sexualidad es todavía objeto de gran simbolismo y ritual y su percepción difiere de la del mundo occidental (Ahlberg, 1994; Nyangondwe, 2005; Shorter, 1998; Heald, 1995). En su estudio no se pueden ignorar las situaciones de pobreza y aislamiento social ni las costumbres y prácticas alrededor de la misma, que han conformado los deseos de los individuos y sus prácticas. En este contexto, a menudo el sexo se ajusta más a unos patrones de comportamiento social que a una elección basada en el deseo individual (Barnett y Parkhurst, 2005). En las sociedades tradicionales se hablaba abiertamente de la sexualidad, porque no era solo un asunto individual, sino también comunitario; por ello, los individuos debían cumplir estrictas normas morales y tabúes para mantener el equilibrio social. La celebración de rituales y sacrificios prevenían o restauraban la ruptura de las normas, a la vez que se ejercía la presión social sobre los grupos de parejas y otras redes sociales para reforzar las conductas socialmente aceptables (Tumbo-Masabo, 1994; Heguye, 1995; Shorter, 1998; Van den Borne, 2005). Vistas como un don divino, y asociadas a la procreación, las relaciones sexuales tenían como finalidad la construcción de la familia y el fortalecimiento de alianzas para incrementar los recursos económicos y la posición social de las mismas.

La entrada a la edad adulta y a la actividad sexual socialmente admitida la determinaban las ceremonias de iniciacion de los jovenes; en las chicas suele realizarse después de la primera menstruación, que, como media, se produce a los 15 años (Munthali y Zulu, 2007). El objetivo del ritual es preparar a la joven para el matrimonio y el cumplimiento de las obligaciones que el mismo comporta; incluyendo los conocimientos y prácticas que el deseo sexual y la habilidad para concebir requieren, priorizando dar placer al hombre sobre el placer de la propia mujer.

La virginidad de la mujer era, y es, un valor muy apreciado en muchas sociedades tradicionales, como Malawi, se velaba por ella, básicamente la familia, para evitar tener que devolver los bienes al novio si la mujer no llegaba virgen al matrimonio, especialmente en las familias patrilineales (Ntukula, 1994; Heguye, 1995; Poku, 2001; Schatz, 2005; Herrera y Campero, 2002; Van den Borne, 2005). La abstinencia y la castidad antes de los 
cambios sociales introducidos por la cristianización y la globalización no representaban gran problema para las jóvenes puesto que el matrimonio solía materializarse poco tiempo despues del ritual de iniciación.

En la cultura malawiana, la sexualidad se asocia con la fuerza física y los alimentos; utilizando metáforas y expresiones vinculadas al gusto y a la comida. Se vive con intensidad y el intercambio de fluidos corporales es percibido como algo «nutritivo», física y emocionalmente; un aporte de «vitaminas» que les da energía vital. Para los individuos la sexualidad es «vida», no tan solo en el aspecto biológico reproductivo; a través de ella también buscan dirigir sus identidades y su sentido del yo como actores sociales y morales (Freeman, 2012; Kaler, 2004; Van den Borne, 2005).

Gobierno e instituciones internacionales involucradas en las políticas del VIH/sida intentan reducir las prácticas tradicionales, pero estas todavía se realizan. Según un estudio de Munthali y Zulu (2007), el 43\% de las chicas y el $33 \%$ de los chicos declararon haber participado en los ritos de paso, siendo la región sur donde más se practican. No obstante, muchas veces se magnifica la importancia del sexo en estas ceremonias y actualmente, con la amenaza del sida, algunas comunidades las han adaptado a la realidad del VIH, como apuntan algunos informantes:

En áreas remotas es difícil para la gente entender a causa de las creencias culturales que tenemos aquí en Malawi, la llamamos kuchotsa fumbi. Se realiza cuando la chica joven crece, con la madurez. Lo primero que hacen es que esta chica tenga sexo, con un hombre mayor, casado. Sí, ahora todavía se hace, pero por detrás, a escondidas, aún creen (Kwima, 38 años).

En algunas zonas, la mayoría rurales, aún se practica, especialmente entre los Lomwe, en el sur (Lawrence, 28 años).

En Malawi, la infidelidad, para los hombres y para las mujeres, es condenada moralmente por la sociedad (Van de Borne, 2005), aunque las relaciones extramaritales son una práctica tolerada y común entre los hombres; forma parte de la construcción de la masculinidad, en menor medida y por distintos motivos, también por las mujeres. La masculinidad se vincula a las habilidades sexuales del hombre; la cantidad de parejas sexuales que tiene y la capacidad para darles soporte económico y 
protección es signo de masculinidad y de estatus económico y social (Cordero, 2013; Frahm-Arp, 2012; Herrera y Campero, 2002). Para el hombre malawiano el sexo es algo primordial, a menudo una fuerza irracional irresistible y un motivo de conversación recurrente en las charlas masculinas (Kaler, 2004). En la dominación sexual masculina, en Malawi, la relación sexual es dirigida por el hombre según sus términos y para su propio placer, según N'gwira et alii, citados en Page (2014), mientras que «la sexualidad femenina es concebida como pasiva y vivida como una mediación para la relación con otra cosa: amor, dinero o estatus social» (Bertran-Dansereau, 2010: 5).

La vinculación sexo-naturaleza y el atributo proteínico del semen hacen que el uso del condón sea visto como «antinatural» porque, además de restar placer a la relación sexual, el semen contiene «proteínas» necesarias para la mujer (Leclerc-Madlala, 2002).

Algunos hombres insisten en no usar condones porque no disfrutan del sexo de la manera que ellos quieren. Algunas chicas no insisten en el uso del preservativo porque solo recibiendo el esperma de los hombres encuentran placer (Maxwel, 32 años).

Aunque el discurso biomédico, que vincula el VIH con la práctica de sexo sin protección, es el que se prioriza en las políticas de prevención y el que predomina entre los jóvenes (Kaler, 2003; Ghosh y Kalipeni, 2007; Chimbiri, 2007), esta construcción de la masculinidad y de la sexualidad hace que el condón sea poco utilizado y pone a las mujeres, especialmente a las jóvenes, en la incapacidad de protegerse del contagio, acentuando la tensión entre el conocimiento y las prácticas de los individuos.

\section{El VIH/sida en escena}

A esta percepción de la sexualidad se enfrenta la realidad del VIH/sida. Desde su descubrimiento, en 1983, la epidemia se extendió a nivel planetario pero el África Subsahariana fue la región más afectada. De los 34,3 millones de personas viviendo con el VIH en el mundo, en 1999, 24,5 millones, el 70\%, se concentraban en el África Subsahariana, y 15,7 eran mujeres (ONUSIDA, 2000). Diecisiete años después, el panorama conti- 
núa siendo desolador. Según UNAIDS (2017), en el año 2016, las cifras seguían manteniendo la misma (des)proporción que en 1999:36,7 millones de personas viviendo con el VIH en el mundo, de las cuales 25,5 millones estaban en el África Subsahariana.

Desde que en 1985 se diagnosticó el primer caso oficial de sida, el VIH se ha convertido en el principal problema de salud en Malawi y en la primera causa de mortalidad entre la población, según Médicos sin Fronteras (2017) y WHO (2015). La prevalencia estimada entre los adultos de 15-49 años pasó del 1,7\%, en 1987, al 16,4\%, en 1999, empezando a declinar a partir de entonces: 14,4\% en 2003 (Geubbels y Bowie, 2006), 10,8\% en 2012 (ONUSIDA, 2013) y 9,2\% en 2016 (UNAIDS, 2017). Una tasa que, a pesar de los programas de divulgación y prevención, solo se ha reducido ligeramente.

La heterogeneidad etnográfica y social del país también supone diferencias geográficas en la prevalencia del VIH; el sur registra dos veces más $(14,5 \%)$ que el centro $(7,6 \%)$ y el norte $(6,6 \%)$. En las zonas urbanas es el doble, $14,6 \%$, que en las rurales, $7,4 \%$, con un $17,8 \%$ versus un $11 \%$ del total de mujeres, respectivamente (MDHS, 2017). Estos datos contradicen los discursos que vinculan las altas tasas de prevalencia con las prácticas tradicionales, llevadas a cabo sobre todo en zonas rurales. Un estudio de Boily et al. (2009) afirma que medir el riesgo de infección del VIH-1, el de Malawi, después de una relación sexual con una persona infectada, es muy difícil, $y$, aunque hay evidencias científicas de riesgo, este no puede ser cuantificado. Dado que las relaciones sexuales en estas prácticas se refieren a un solo contacto, y suponiendo que el hombre estuviera infectado, el contagio por un solo coito es bajo, habitualmente de un 0,001 a 1 de probabilidades por 1.000 contactos, según un análisis de Powers et al. (2008).

\section{Resultados de la investigación}

Al inicio del trabajo la muestra no buscaba perfiles específicos, pero durante el desarrollo de la investigación se fueron concretando tres perfiles distintos de mujeres, que se corresponden con tres etapas de su ciclo vital.

a) La adolescencia: chicas contagiadas por vía materna; todas ellas adheridas a programas especiales de divulgación para el conocimiento y la 
prevención. Tanto en LMH como en HBC, además del tratamiento antirretroviral mensual, se les ofrece soporte material: alimentos básicos y ayuda económica para el transporte.

b) La reproducción: jóvenes madres, diagnosticadas en los controles antenatales, obligadas a realizar la prueba del VIH para la asistencia prey postnatal. Son mujeres casadas, contagiadas, casi todas, por el marido, del cual dependen, que afrontan una situación compleja al recibir el diagnóstico; comunicar su estado al esposo, negociar unas relaciones sexuales seguras y el miedo a sus infidelidades les generan gran tensión y ansiedad.

c) La viudedad: un grupo heterogéneo de mujeres, entre los 38-70 años, que dependen, en gran parte, de la asistencia de las asociaciones cristianas y de la red social de la comunidad para su subsistencia.

A pesar de las diferencias de edad y del ciclo vital, los tres perfiles tienen factores comunes: son portadoras del virus y sufren violencia estructural; esa violencia, no siempre visible, causada por los procesos de estructuración social, y que no necesita, obligatoriamente, de ninguna forma de violencia directa para tener efectos negativos sobre las oportunidades de supervivencia, bienestar identidad y/o libertad de las personas (Galtung, 1996).

\subsection{Adolescencia. Silencio, miedo al estigma y a la discriminación}

Casi todas las entrevistadas dicen haber sido contagiadas por su madre, al nacer, y todas reciben tratamiento antirretroviral. La mayoría tiene a más miembros de la familia infectados y forman parte de los 670.000 huérfanos que hay en el país (UNAIDS, 2016). Dicen ocultar su condición de seropositivas por miedo al estigma y a la discriminación. La construcción del estigma suele contraponer la existencia de un grupo ajeno (los infectados) al considerado como verdadero (los no infectados), y debe hacer referencia a elementos diferentes y propios de ese grupo objeto de estigma que lo hacen muy distinto (Goffman, 2012); por ello el estigma es utilizado para hacer referencia a un atributo profundamente desacreditador, el VIH, y equivale al rechazo social del individuo. Los afectados tienden a sentirse «diferentes», lo que puede llevar a una baja autoestima 
y a valorar poco la vida, aumentando las conductas de riesgo (Delavande et al., 2014). Por eso, los adolescentes son avisados por sus padres o tutores para que no revelen su situación.

Ocultar el estatus de seropositivo puede tener consecuencias negativas para los individuos en general, pero especialmente para los adolescentes, pues la adolescencia es una etapa de gran vulnerabilidad, con importantes cambios físicos y emocionales, y en la que el soporte parental es menor. Afrontar una enfermedad crónica como el VIH puede llevar al individuo a incorporar el estigma y la discriminación, produciéndole ansiedad y depresión, provocando la interrupción del tratamiento. Según Parienti (2014), en general, el 37,7\% de los individuos jóvenes viviendo con el VIH no tiene adherencia al tratamiento, que, además de tomar la medicación pautada, requiere visitas regulares al hospital y asistir a los programas y actividades que se realizan en los VCT (Voluntary Counseling and Testing) y otras organizaciones para adolescentes que promueven el conocimiento del VIH, la eficacia del sexo seguro y el uso de preservativos para reducir el riesgo de contagio (Tabatabai et alii, 2014). Un estudio de Kim et alii (2017) entre adolescentes viviendo con el VIH, en Malawi, concluye que el «olvido» es la causa más frecuente de la interrupción; pero la depresión, el agobio y el miedo al estigma también aparecen entre los argumentos. Otro estudio de Zolowere et alii (2008) demuestra que los pacientes, hombres de una media de edad de 31 años, diagnosticados de tuberculosis, enfermedad relacionada con el VIH, solo revelaron su diagnóstico a familiares cercanos y personas de confianza por miedo a la estigmatización; algunos de ellos, bajo tratamiento antirretroviral, ocultaron el tema de la medicación a sus compañeros pacientes y ninguno lo había comunicado a sus hijos.

Clara tiene 20 años, vive con una hermana casada, estudia tercer curso de secundaria y, al contrario que muchas de las entrevistadas, entra en detalles sobre la sexualidad:

Yo nací así, mi madre murió cuando yo nací [...] mi padre es positivo; fue él quien me dijo que yo era positiva, hace 10 años [...], es cuando empecé a tomar medicinas, yo no estaba muy feliz por esto, por haber nacido así, pero ahora lo entiendo, por eso vengo al Club. Toda mi familia sabe 
mi estatus, pero no mis amigos [...] porque mis amigos podrían reírse, por eso no lo digo.

No, no tengo novio. Cuando lo tenga se lo diré si nos vamos a casar, para ser tratados como una pareja, para hacer una familia.

Sí, es el profesor de la asignatura Life Skills quien nos enseña acerca del VIH, cómo protegernos [...], algunos utilizan la información que nos dan en clase, pero a otros no les importa su vida.

Yo creo que las chicas tienen menos cuidado, a causa de la pobreza y la falta de recursos en casa, porque para los pobres, si en casa son pobres [...], piensan si voy con un hombre me va a dar mucho dinero [...], si me ofrecen 5.000 kwachas $^{9}$ con condón o 10.000 kwachas sin condón, que es mucho más [...] por lo tanto ellas usan el dinero para la familia, pero también lo usan para cosas personales. A veces pueden estar dos o tres días yéndose a dormir sin cenar. Encuentran a hombres en sitios como el autobús, pero es por la pobreza.

Sí, a los hombres les gusta más sin protección, maswiti samadyera mu pepala, sino es como comer un caramelo con un papel de plástico [...], no les importa [el riesgo de infección].

Memory, de 16 años, vive con su hermana y sabe pocas cosas de sus padres. La hermana, casada, también es seropositiva, el marido no lo es:

Iba mucho al hospital cuando era pequeña, estaba enferma y me llevaban para revisiones. A los 6 años me lo dijeron, pero yo no sabía nada de esto, no sabía qué era el VIH. Cuando crecí, el doctor de Lighth House me dijo que no podía dejar de tomar las medicinas: «Si las tomas vivirás mucho, pero si dejas de tomarlas te morirás». Por eso las tomo.

No sé [cómo se contagió], quizá por mi hermana, tal vez porque he vivido mucho tiempo con mi hermana, no se mucho de mis padres. Ella es positiva.

No, no se lo he dicho a nadie, solo a mi hermana [...], por el estigma y la discriminación, porque aquí, en Malawi, si lo saben, las personas lo pueden pregonar en todas partes; en el mercado [...], porque es mi vida y nadie tiene que saberlo. Cuando tenga novio sí le diré que soy positiva, algunos chicos aceptan, pero otros se marchan.

9 Según el cambio actual, estas cantidades corresponderían a unos 6 y 12 euros, respectivamente ( $<$ www.xe.com/es/currencyconverter/convert $/$ ?Amount $=5000 \&$ From $=\mathrm{MWK} \& \mathrm{To}=\mathrm{EUR}>$ ). 
No, no tengo novio, pero en el colegio sí tengo amigas que tienen y hacen el amor, yo no. Sí, las chicas hablan acerca de los condones, algunas van a planificación familiar para tomar anticonceptivos [...], pastillas. Algunos chicos sí aceptan usar condones, pero otros no [...], no los usan porque no piensan en su vida, solo quieren disfrutar y ponen su vida en peligro.

El nivel de conocimiento del VIH entre los jóvenes es alto; los temas de prevención y riesgo de contagio forman parte curricular de la enseñanza, en la asignatura Life Skill Education. Los anuncios institucionales en televisión y radio, el medio de comunicación masivo en las zonas rurales, así como los pósteres en todos los centros de salud y los mensajes en los libros de texto, están presentes en el día a día de los individuos, predominando en ellos el modelo biomédico.

El 13\% de las chicas y el 22\% de los chicos de 15-19 años tienen su primer contacto sexual antes de los 15 años (MDHS, 2017), pero las entrevistadas confiesan no tener relaciones sexuales; sí se refieren a terceros, compañeros de colegio casi siempre, que sí las tienen; esto puede interpretarse como una afirmación a través de esos «otros».

Los adolescentes tienen pocos espacios públicos, al margen de los que ofrecen las instituciones, para socializar, muchos de ellos estudian en boarding schools, internados, que acostumbran a estar apartados de las zonas urbanas. La iglesia, la mezquita o los campos de fútbol son espacios donde la gente joven suele concentrarse y realizar actividades diversas, siendo la escuela el lugar donde muchos comienzan sus primeras relaciones, que denominan chibwenzi, literalmente, amistad (Kaler, 2003), pero que también pueden entenderse como relaciones que van más allá; como tener un novio o novia, aunque esta no acabe en matrimonio. Iniciar la relación requiere un «protocolo». Es el chico quien propone a la chica ser su chibwenzi, si ella acepta, queda implícita la aceptación de tener sexo. En el Malawi rural, las relaciones íntimas se entrelazan con dinero, cosa no vista como inmoral o como signo de explotación sexual (Poulin, 2007; Tawfik y Watkins, 2007); muchas mujeres argumentan que es el amor y no el dinero y los regalos lo que las mueve a tener relaciones sexuales, $y$, aunque pueden negarse, suelen aceptar las propuestas para aumentar su 
popularidad en el grupo, disponer de objetos como jabón o cremas que mejoren su estatus social y que la familia no puede pagarles. El concepto de masculinidad deja claro que la responsabilidad de los muchachos es proveer de beneficios materiales a sus parejas, porque socialmente eso está ligado a las obligaciones que se espera que cumplan los maridos.

A pesar del conocimiento del riesgo de contraer el VIH y de embarazo, pocos adolescentes se protegen; mientras los chicos argumentan maswiti samadyera mu pepala (no quiero utilizar condón), ellas no suelen oponerse a estas relaciones de riesgo, por temor a que la relación se rompa o por una concepción romántica del amor.

Lo que pasa es que el chico crece y quiere tener sexo con una chica; puede no querer utilizar condones, incluso si puede tener condones no está satisfecho, porque quiere saber lo que se siente [...], es por eso por lo que la mayoría de los hombres jóvenes no usan condones. Aquí en Malawi la chica acepta al chico por lo que el chico es. Por lo tanto, si él quiere tener sexo sería muy difícil porque ella no quiere perder lo que ve [...], no, no es prostitución. Lo que pasa es que en muchos casos las relaciones se mueven por el dinero, si el hombre tiene cash, dinero, para la chica es muy difícil (Kwima, 38 años).

Por la presión del grupo, los adolescentes, especialmente los hombres, son más susceptibles a asumir riesgos y el beneficio del riesgo prima por encima del coste que este supone (Gardner y Steinberg, 2005; MacPhail y Campbell, 2001). Algunos jóvenes «presumen» de ser seropositivos como un signo de masculinidad (Kaler, 2003). Carol, de 17 años, comentó que entre sus compañeros de colegio «tener VIH estaba de moda», aunque matizó que en la escuela les recomiendan la fidelidad y el uso de condones para evitar el contagio. En este contexto se entiende la alta tasa de prevalencia entre los jóvenes: el 3\% de las mujeres de 15-17 años y cerca del 10\% entre las de 23-24 años versus el 0,7\% y el 2\% entre los hombres del mismo rango (MDHS, 2017).

Las instituciones religiosas entienden la sexualidad como «un regalo de Dios» (Shorter, 1998; Bertrand-Dansereu, 2010), y sus discursos sobre la prevención del contagio continúan centrándose en la castidad. A partir de la década de los noventa, coincidiendo con el punto álgido de la 
epidemia, sus mensajes intentan hacer una aproximación holística en la educación sexual de los adolescentes. «Evidentemente, se centran en la abstinencia sexual hasta el matrimonio, pero su objetivo es que los jóvenes tengan respeto por su propia sexualidad y que la abstinencia sea vista como un esfuerzo constante y no simplemente como la ausencia de un acto inmoral» (Bertrand-Dansereu, 2010: 102).

\subsection{La reproducción. ¿Revelar o no el estatus al marido? Miedo al abandono}

Una gran proporción del contagio ocurre en matrimonios o parejas estables, y ante la ausencia de un remedio definitivo para la curación, la prevención es la única arma eficaz para luchar contra el VIH/sida (Anglewicz y Chintsanya, 2011; Gipson et al., 2010)we use individual and couples-level data for currently-married respondents from an ongoing longitudinal study in rural Malawi to (1. Por eso cada vez se destinan más recursos a programas de VCT y a la planificación familiar, porque se ha demostrado que estas intervenciones son las más eficientes, en términos de coste-efectividad, en la reducción del contagio. A pesar de ello, muchos individuos solo realizan la prueba si muestran signos de enfermedad.

Cuando van a hacerse la prueba, la mayoría de las mujeres están enfermas, cuando empiezan a sentir síntomas, yo misma, cuando empecé a sentir los síntomas, no antes. Muchas no van porque exteriormente parecen estar sanas, por el estigma [...], porque se sienten cómodas con su cuerpo, por eso esperan a estar enfermas. Entonces van para la prueba de sangre (Mwali, 38 años).

El conocimiento sobre la planificación familiar entre las mujeres adultas es elevado, aunque el $69 \%$ de las mujeres casadas no utilizan ningún método anticonceptivo; un alto porcentaje de las que sí lo hacen, 37\%, discontinuaron el tratamiento durante los cinco años anteriores a la encuesta de salud (MDHS, 2017). La inyección es el método preferido por las mujeres casadas (el 30\%); al ser una dosis mensual, tienen un mayor control propio y es más fácil evitar que el marido lo sepa. Anticonceptivos como el DIU, que implican reglas más largas y abundantes, son descarta- 
dos por la mujer, que teme que el marido busque sexo fuera del matrimonio, al tener que esperar más tiempo para mantener relaciones sexuales (Bisika, 2008).

Mphatso, con problemas auditivos, narra su experiencia asistida por su hermana. Tiene 32 años y lleva en brazos a dos niños gemelos de un mes, envueltos en trozos de chitenje $e^{10}$.

Tiene 6 hijos y fue diagnosticada en 2014, con el embarazo del hijo anterior. Responsables del hospital fueron al poblado a hablar con la familia para iniciar el tratamiento, probablemente en 2016. Diez meses después de dar a luz quedó embarazada de los gemelos. Tan solo uno de los hijos ha sido testado y confirmado negativo y ambos están bajo seguimiento.

El marido, también positivo, es violento [...], él no está bajo tratamiento, pero le roba las medicinas a ella, como consecuencia, ella no toma el tratamiento completo a final de mes. Su marido no cuida a su mujer, ni durante el embarazo [...]; el marido no cuida a su familia, es un irresponsable.

Fue difícil para todos saber que era positiva. Como tiene este problema de audición..., es sorda y además está infectada. Es dependiente y lo será siempre, es duro para ella. Los familiares tienen que responsabilizarse de ella y los niños.

$¡$ ¡Ah! Ella se queja de que su marido no los utiliza (condones). El fin de semana se marcha a Mzuzu para relajarse, lo que significa que tiene otras relaciones y no utiliza condones; es un hombre difícil.

Este fue un caso dramático por la extrema pobreza de la familia y lleva a reflexionar sobre las palabras de Farmer (2003: 44): «Las mujeres están en situación de mayor riesgo de VIH porque la pobreza es la principal y determinante condición de sus vidas».

Kiweta tiene 26 años y tres hijos; el último está bajo tratamiento:

Fui diagnosticada en 2015, mi marido, en 2016. Creo que podría haber sido infectada por mi marido, porque pudo esconder los resultados inicialmente, que era positivo. Yo oía rumores de que iba con prostitutas antes de 2015, se comportaba mal. Él me decía que no, que no era verdad.

10 El chitenje es una pieza de tela que las mujeres llevan colocada como un pareo/falda, encima de la ropa. 
Él fue solo al hospital y dijo que estaba bien. Cuando yo fui diagnosticada nos trataban como pareja discordante porque él no enseñó su health passport [cartilla sanitaria], dijo oralmente que estaba bien. Al principio no quería decírselo, estaba deprimida, tenía miedo, recordaba su comportamiento, pero cuando se lo comuniqué él reaccionó bien, me dijo: «OK, mi esposa, yo lo acepto». Cuando lo dije a mi familia ellos lo aceptaron bien, me regalaron un teléfono. Mi marido vende carbón, es el único trabajo que tiene. No, no utilizamos condones, él no disfruta, maswiti samadyera mu pepala, es mejor abrir el papel.

Las informantes afirman haber revelado a sus maridos su estatus de seropositiva una vez facilitado el diagnóstico, aunque este no hubiera sido conjunto, pero no siempre lo hacen de forma inmediata por el temor al abandono. Según Anglewicz y Chintsanya (2011), en las zonas rurales, en general, las mujeres están más predispuestas a revelar su estatus a sus maridos que los hombres a sus mujeres, y, cuando lo hacen, el marido casi siempre lo acepta, aun así, impera el miedo a la ruptura de la relación y a la pérdida del sustento económico. El relato de uno de los médicos entrevistados es ilustrativo:

Una mujer que vivía con su novio, sin estar casados, en 2008, dejó el tratamiento durante cuatro años; dijo que no lo podía seguir a causa del hombre. Ha vuelto este año y le pregunté el motivo. Comentó que el hombre se marchó a Mozambique y ella lo acompañó para vivir juntos, venía sola...; el hombre es negativo. Yo le dije que debía continuar el tratamiento inmediatamente y que debían utilizar condones porque eran pareja.

La mujer envió al hombre a recoger la medicación para ella y él quiso conocer más detalles, yo le expliqué que ella era positiva y cómo debían tratarse, no le expliqué acerca del pasado de ella para evitar conflictos, «ahora estáis juntos», le dije. El hombre lo entendió y continuó ayudando a la mujer (Francis).

Las primeras acciones de planificación familiar y promoción de preservativos las promovieron organizaciones extranjeras, en 1960, pero la condena del Gobierno demoró su implementación hasta 1994. Desde sus inicios, el condón ha sido motivo de controversia. La construcción social 
del matrimonio, percibido como una etapa cuyo fin es tener hijos y en el que la confianza y el amor entre esposos deben imperar, ha hecho que desde el Estado y la comunidad se haya condenado su uso, aduciendo cuestiones morales. Asociado al sexo de pago, los esposos no hablan del tema a pesar de conocer el riesgo de contagio; el condón es considerado un «intruso», algo que converge con la política del Gobierno, que admite su utilización en parejas discordantes o si se tienen múltiples parejas (Van den Borne, 2005; Chimbiri, 2007), y su uso todavía no es significativo. En LMH, cuando una mujer es diagnosticada como seropositiva, se intenta involucrar al marido o pareja, para que el tratamiento sea conjunto, $y$, en el caso de ser pareja discordante, aun prevaleciendo el mensaje cristiano de fidelidad mutua, recurren al personal médico laico para la recomendación del uso de condones o, en según qué casos, otros métodos anticonceptivos.

\subsection{La viudedad. La lucha por la subsistencia}

Las ayudas económicas del Gobierno a las personas enfermas o discapacitadas, como es el caso de muchas mujeres viudas, en las zonas rurales, son casi nulas. Por ello, muchos individuos de estos colectivos dependen del apoyo de la red social facilitada por la comunidad, especialmente en tiempos de escasez alimentaria que periódicamente asolan al país, por ello su supervivencia depende del grado de aceptación del individuo en la misma. Algunas mujeres ven en el matrimonio la posibilidad de evitar la exclusión y pobreza, y esto puede llevarlas a aceptar proposiciones de matrimonio sin conocer bien al hombre e incluso sin saber si cuenta con los recursos necesarios para mantener a la familia (Van den Borne, 2005; Verheijen, 2011). El testimonio de Shakira, de 38 años y tres hijos, con los que vive, es una muestra de cómo algunas mujeres ven en el matrimonio la opción de salir de la pobreza.

Fui diagnosticada en el 2003, cuando fui a revisión por el embarazo de mi tercer hijo. Yo pienso que fui contagiada por mi marido, que murió en 2006, antes de que naciera mi hija, nunca se hizo la prueba o tal vez se la hizo y nunca me lo dijo porque tal vez tenía miedo de que yo me fuera con mi madre. Si me lo hubiera dicho yo habría continuado con él; 
estaba casada. Me casé con él porque era pobre, quería que me ayudase con los school fees. Él era viudo, no sé cuándo murió su mujer. [...] no, no sé de qué murió.

Sí, lo dije a mi familia y reaccionaron bien [...], no te preocupes, me dijeron. Me están ayudando. Solo lo dije a mis familiares. Otra gente habla, habla, cuando lo dices a alguien a quien amas, esperas que no lo diga a nadie más.

Algunos hombres no quieren usar condones porque dicen que no se sienten bien, pero otros ahora sí los usan. Las mujeres somos vulnerables, tenemos que cuidar a la familia. Nosotras somos las que cuidamos a la familia, porque el hombre trabaja fuera. Cuando nos pasa algo a nosotras no decimos nada a nadie.

Mzukira tiene 65 años y ocho hijos:

Creo que me infecté en el 2000, estaba en Blantyre y enfermé, tenía diarrea. En 2003, en el Queen Elizabeth Hospital, me dijeron que tenía tuberculosis, allí no tenían tratamiento. En 2004 vine a Lilongwe y fui admitida en Kamuzu Hospital, allí me hicieron la prueba de VIH, que dio positivo y empecé el tratamiento. Creo que lo contraje por mi marido, es conductor de camiones ${ }^{11}$ y estaba siempre moviéndose. Yo le decía a mi marido que se lo hiciese, pero decía que él no podía tener el virus. Estaba enfermo, pero no quiso hacerse la prueba, murió en marzo de 2002.

Para él era difícil de aceptar, sabía que si las mujeres sabían que era positivo huirían y él, como conductor de camiones, tenía varias relaciones. Tomó la decisión, no lo aceptó. Sabía que mucha gente debería de tener el virus.

Una de sus hijas, de 22 años y casada, también es seropositiva:

Pienso que ha contraído el virus por su marido, que era viudo cuando se casó con mi hija y su primera mujer murió de sida, pero el marido no se ha hecho la prueba. Tienen tres hijos: el primero y el segundo son positivos, el tercero está bien.

11 Los conductores de camiones son considerados población de alto riesgo en las políticas de prevención. 


\section{Conclusión}

El análisis permite concluir que los mensajes oficiales de prevención, basados en la abstención, fidelidad y «condomización» (Barnetty Parkhurst, 2005; Verheijen, 2011) y en la condena de las prácticas tradicionales llegan a gran parte de la población; los individuos conocen la enfermedad y los métodos para prevenirla.

Aunque el grado de conocimiento es alto, los individuos no están muy concienciados y se exponen al riesgo de contagio por diferentes motivos; las mujeres sí suelen percibir la práctica del sexo sin protección como un factor de riesgo, pero la falta de recursos económicos las lleva a tener sexo transaccional y a aceptar prácticas sexuales poco seguras, al negárseles la agencia para rechazarlas. En el caso de los hombres la percepción del riesgo es distinta, especialmente entre los jóvenes, que, por el hecho de serlo, creen estar «a salvo», y perciben una probabilidad de contagio baja, pues, según Douglas (1996: 58), «se tiende a ignorar los peligros cotidianos y a restar importancia a los más infrecuentes [...] como consecuencia del sentido adaptativo de inmunidad subjetiva el individuo».

Para las adolescentes, al inicio de la sexualidad debería acompañarlo una buena educación sexual, impartida por profesionales, que complementase las explicaciones curriculares, y el acceso fácil y confidencial a los servicios de planificación familiar. Esto las ayudaría a conocer y respetar mejor sus cuerpos, su propia sexualidad, y a evitar algunas conductas de riesgo, así como a reducir la alta tasa de embarazos adolescentes. Que estos servicios fueran impartidos en las comunidades locales, involucrando a sus responsables, es algo que las informantes han expresado. Una relación más cercana y directa aportaría a los jóvenes de ambos sexos, el grueso de la población, el capital social necesario que les permitiera apoyarse en unas relaciones durables para mantener la adhesión y cohesión al grupo, a la vez que reduciría el estigma y la discriminación.

La feminización del sida no se debe tanto a las prácticas culturales, como enfatizan los mensajes oficiales, como al sistema patriarcal dominante. El problema no es la conducta de las jóvenes y de las mujeres, sino la construcción de la masculinidad que legitima el comportamiento sexual del hombre: múltiples parejas, prostitución y violación en el ma- 
trimonio y la negativa a utilizar condones en las relaciones sexuales, anteponiendo la satisfacción personal a la protección. Todo ello incrementa, de forma desproporcionada, el riesgo de contraer el VIH/sida por parte de las mujeres que no pueden ejercer su agencia, porque, precisamente por ser mujeres y pobres, la tienen más restringida.

\section{Bibliografía}

ACNUR (2017). Disponible en: <https:/eacnur.org/es/actualidad/noticias/emergencias/cuales-son-los-paises-mas-pobres-del-mundo>.

AhlBERG, Beth Maina (1994). «Is there a distinct african sexuality? a critical response to Caldwell et alii». Africa, 64 (2), 220-242.

Anglewicz, Philip y Chintsanya, Jesman (2011). «Disclosure of HIV Status Between Spouses in Rural Malawi». AIDS Care, 23 (8), 998-1005.

Banco Mundial (2016). Disponible en: <https://datos.bancomundial.org/ pais $/$ malawi?view=chart $>$.

Banco Mundial (2018). Préstamos de la Asociación Internacional del Fomento.

Disponible en: <https://datos.bancomundial.org/pais/malawi>.

Barnett, Tony y Parkhurst, Justin (2005). «HIV/AIDS: sex, abstinence, and behaviour change». The Lancet Infectious Diseases, 5 (9), 590-593.

BBC. Mundo News digital. Disponible en: <http://new.bbc.co.uk/hi/spanish/news/newsid 1950000/1950772.stm>.

BBC News. Disponible en: <http://www.bbc.com/news/world-africa-38028065>.

BELDA, R. (1975). «Manipulación social del hombre». Iglesia Viva, 57, mayo-junio, 260-271.

Bertrand-Dansereau, Anaïs (2010). La prévention du vih auprès des jeunes au malawi: paralysie et potentiels de l'éducation sexuelle. Université du Québec Montréal.

BISIKA, Thomas (2008). «Cultural factors that affect sexual and reproductive health in Malawi». J. Fam Plann Reprod Health Care, 34 (2), 79-81.

Bochow, Astrid y VAN Dijk, Rijk (2012). «Christian Creations of New Spaces of Sexuality, Reproduction, and Relationships in Africa: Exploring Faith and Religious Heterotopia». Journal of Religion in Africa, 42 (4), 325-344. 
Boily, Marie-Claude; Baggaley, Rebecca; Wang, Lei; Masse, Benoit; White, Richard; Hayes, Richard J. y Alary, Michel (2009). «Heteroseuxal risk of HIV-I infection per sexual act: systematic review and meta-analysis of observational studies». The Lancet Infectious Deseases, 9 (2), 118-129.

Chimbiri, Agnes M. (2007). "The condom is an "intruder" in marriage: evidence from rural Malawi». Social Science and Medicine, 64 (5), 11021115.

Cordero, Julia (2013). "When the group encourages extramarital sex: Difficulties in HIV/AIDS prevention in rural Malawi». Demographic Research, 28 (30), 849-880. Disponible en: <http//.www.demographicresearch.org>.

Delavande, Adeline; Sampaio, Mafalda y Sood, Neeraj (2014). «HIV-related Social Intolerance and Risky Sexual Behaiour in a High HIV Prevalence Environment». Social Science and Medicine, 111 (6), 84-93. doi: 10106/j. socscimed.2014.04.011.

DelVecchio Good, Mary-Jo; Hyde, Sandra Teresa; Pinto, Sarah y Good, Byron (2008). «Postcolonial Disorders: Reflections on Subjectivity in the Contemporary World». En Mary-Jo Good et alii. Postcolonials Disorders (pp. 1-40). University of California Press.

Douglas, Mary (1996). La aceptabilidad del riesgo según las ciencias sociales. Barcelona: Ediciones Paidós.

FAO(2017). Disponibleen:<http://www.fao.org/faostat/es/\#country/130>. FARMER, Paul (2000). «Desigualdades sociales y enfermedades infecciosas emergentes». Papeles de población, 23, 181-201. Toluca, México: Universidad Autónoma del Estado de México.

FARMER, Paul (2003). «On Suffering and Structural Violence. Social and Economic Rights in the Global Era». En Pathologies of Power. Health, Human Rights, and the New War on the Poor. Berkeley: University of California Press.

FREEMAN, Emily (2012). Older adults experiences of ageing, sex and HIV infection in rural Malawi. Tesis doctoral. Ernestina Coast, supervisora de la tesis. Londres: Escuela de Economía y Ciencias Políticas.

FoucAult, Michel (1998). Historia de la Sexualidad. La Voluntad del saber. Madrid: Siglo XXI Editores. 
Frahm-Arp, Maria (2012). «Singleness, Sexuality, and the Dream of Marriage». Journal of Religion in Africa, 42 (4), 369-383.

Gardner, Margo y Steinberg, Laurence (2005). «Peer Influence on Risk Taking, Risk Preference, and Risky Decision Making in Adolescence and Adulthood: An Experimental Study». Developmental Psychology, 41 (4), 625-635.

Galtung, Johan (1996). Peace by peaceful means. Peace and conflict, development and civilization. London: Sage

GALTUNG, Johan (1971). «A structural theory of imperialism». Journal of Peace Research, 8 (2), 81-117.

Geubbels, Eveline y BowIE, Cameron (2006). «Epidemiology of HIV/AIDS in adults in Malawi». Malawi Medical Journal, 18 (3), 99-121.

Gipson, Jessica; Muntifering, Carie; Chauwa, Felluna; Raulo, Frank; Tsui, Amy y Hindin, Michelle (2010). «Assessing the Importance of Gender Roles in Couples' Home- Based Sexual Health Services in Malawi». African Journal of Reproductive Health, 14 (4), 63-73.

Goffman, Erving (2012). Estigma: la identidad deteriorada. Buenos Aires: Amorrortu Editores.

HEALD, Suzette (1995). «The power of sex: some reflections on the Calwell's "African Sexuality" thesis». Journal of the International African Institute, 65 (4), 489-505.

Ghosh, Jayati y KaLIPENI, Ezequiel (2007). «Concern and practice among men about HIV/AIDS in low socieconomic income areas of Lilongwe, Malawi». Social Science and Medicine, 64 (5), 1116-1127.

Heguye, Eli S. (1995). «Young People's Perception of Sexuality and Condom Use in Kahe». En Knut-Inge Klepp, Paul M. Biswalo y Aud Talle (eds.). Young People at Risk. Fighting AIDS in Northern Tanzania (pp. 107-120). Osla: Scandinavian University Press.

Herrera, Cristina y Campero, Lourdes (2002). «La vulnerabilidad e invisibilidad las mujeres ante el VIH/sida: constantes y cambios en el tema». Salud Pública de México, 44 (6), 554-563.

KALER, Amy (2003). "My girlfriends could fill a yanu-yanu bus": Rural Malawian Men's Claims About Their Own Serostatus». Demographic 
Research. Special Collection, 9 (suppl. 1), 349-72. doi: 10.4054/DemRes. S1.11,

KALER, Amy (2004). «AIDS-talk in everyday life: the presence of HIV/AIDS in men's informal conversation in Southern Malawi». Social Science and Medicine, 59 (2), 285-297.

Kim, Maria; Mazenga, Alick; Yu, Xiaoying; Ahmed, Saeed; Paul, Mary; KaZembe, Peter y ABrams, Elaine (2017). «High self-reported nonadherence to antiretroviral therapy amongst adolescents living with HIV in Malawi: barriers and associated factors». Journal of the International AIDS Society, 20 (1), 1-12. Disponible en: <http://dx.doi. org/10.7448/IAS.20.1.21437>.

LeClerC-Madlala, Suzanne (2002). «Youth, HIV/AIDS and the importance of sexual culture and context». Centre for Social Scienc Reseach. Aids and Society Research, unit 9 - June.

Likuni Mission Hospital (2017). 2016 Annual Report.

Matiki, Alfred J. (2001). «The social significance of English in Malawi». World Englishes, 20 (2), 201-218.

MaCPhail, Catherine y CAmpbell, Catherine (2001). "I think condoms are good but, aai! I hate those things": Condom use among adolescents and young people in a Southern African township». Social Science and Medicine, 52 (11), 1613-1627.

Madunagu, Bener E. (2001). «Women's Alternatives in the New Era». Politica Internazionale. January-April, 63-69.

MacCracken, John (2012). A History of Malawi 1859-1966. New York: James Currey.

Morris, Brian (2011). «Medical herbalism in Malawi». Anthropology and Medicine, 18 (2), 245-255.

Médicos sin Fronteras (2017). Disponible en: <https:/www.msf.mx/ country-region/malawi>.

Munthali, Alister y Zulu, Eliya (2007). «The timing and role of initiation rites in preparing young people for adolescence and responsible sexual and reproductive behaviour in Malawi». African Journal for Reproductive Health, 11 (3), 150-167. 
National Statistics Office (NSO) and ICF (2017). Malawi Demographic and Health Survey 2015-2016. Zomba, Malawi/Rockville, Marylad, USA. NSO/ICF.

Ntukula, Mary (1994). «The initiation rite». En Zubeda Tumbo-Masabo y Rita Liljeström (eds). Chelewa, Chelewa. The Dilemma of Teenage Girls (pp. 96-115). Sweden: Scandinavian Institute of African Studies.

NyANGondwe, Rachel (2005). Coming of Age. Malawi: Kachere Series.

ONUSIDA (2000). Informe sobre la epidemia mundial de VIH/sida. ONUSIDA (2013). Informe mundial sobre la epidemia mundial de sida 2013.

Отоsson, Daniel (2017). Homofobia de Estado. Un Estudio mundial de las leyes que prohiben la actividad sexual con consentimiento entre presonas adultas. Informe inédito. ILGA. Asociación Internacional de lesbianas y gays. Disponible en: <http://ilga.orges/informe-homofobia-estado>. PAGE, Samantha (2014). "Narratives of Blame» HIV/AIDS and Harmful Cultural Practices in Malawi: Implications for Policies and Programmes. Tesis doctoral. Tony Chafer, Saseendran Pallikadavath y Tamsin Bradley, directores de la tesis. Portsmouth: Universidad de Portsmouth. Departamento de Filosofía.

PARIENTI, Jean J. (2014). «The case of adherence in the youth: Rebel without a cause?» AIDS, 28 (13), 1983-1985. doi: https://doi.org/10.1097/ QAD.0000000000000317.

PokU, Nana (2001). «Africa's AIDS crisis in context: "how the poor are dying"». Third World Quarterly, 22 (2), 191-204.

Poulin, Michelle (2007). «Sex, Money and Premarital Relationships in Southern Malawi». Social Science \& Medicine, 65 (11), 2383-2393. doi: 10.1016/j.socscimed 2007.05.030.

Powers, Kimberly A.; Poole, Charles; Pettifor, Audrey y Cohen, Myron S. (2008). «Rethinking the heterosexual infectivity of HIV-1: a systematic review and meta-analysis». The Lancet Infectious Diseases, (8), 553-563.

Rankin, Sally; Jong, SoSon; Matovu, Schola; Youmans, Sharon y Lindgren, Teri (2016). «Sources of Social Capital for Malawi People Living With HIV». Global Qualitative Nursing Research, 3, 1-10. doi: 10.1177/2333393616676432. 
Record, Richard; Kumar, Praveen y Kandoole, Priscilla (2018). From Falling Behind to Catching Up A Country Economic Memorandum for Malawi. Washington, DC: The World Bank.

SANCHIZ, Pilar (1995). «Poder de la palabra y eficacia de los objetos. Pentecostalismo y "costumbre" en Guatemala». Iglesias, pueblos y culturas, 36, 43-69.

SCHATz, Enid (2005). «Take your mat and go!: Rural Malawian women's strategies in the HIV/AIDS era». Culture, Health and Sexuality, 7 (5), 479-492.

Shorter, Aylward (1998). Celibacy and African Culture. Kenya: Franciscan Kolbe Press.

Tabatabai, Julia; Namakhoma, Ireen; Tweya, Hannock; Phiri, Sam; Schnitzler, Pauly NeuhanN, Florian (2014). «Understanding reasons for treatment interruption amongst patients on antiretroviral therapy. A qualitative study at the Lighthouse Clinic, Lilngwe, Malawi». Global Health Action. doi: https://doi.org/103402/gha.v7.24795.

Tawfik, Linda y Watkins, Susan (2007). «Sex in Geneva, sex in Lilongwe, and sex in Balaka». Social Science and Medicine, 64 (5), 1090-1101.

Tumbo-Masabo, Zubeida (1994). «Too little too late. En Zubeida TumboMasabo y Rita Liljeström (eds). Chelewa, Chelewa. The Dilemma of Teenage Girls (pp. 150-169). Sweden: Scandinavian Institute of African Studies. UNAIDS (2016). Country fact sheets Malawi. Disponible en: <http://www. unaids.org/en/regionscountries/countries/malawi>.

UNAIDS (2017). Unaids data. Global Report. Disponible en: <http://www. unaids.org/sites/default/files/media_asset/20170720>.

VAN DEN BORNE, Francine (2005). Trying to survive in times of poverty and AIDS. Women and multiple partners sex in Malawi. Publicado en la serie: Health, Culture and Society: Studies in Medical Anthropology and Sociology. Editores: Els van Dongen, Ssjaak van der Geest y Paul ten Have. Amsterdam.

VerheiJen, Janneke (2011). «Complexities of the "transactional sex" model: non-providing men, self-providing women, and HIV risk in rural Malawi». Annals of Anthropological Practice, 35, 116-131. doi: 10.1111/j.21539588.2011.01070. 
Walther, Selma (2017). «Moral hazard in marriage: the use of domestic labor as an incentive device». Review of Economics of the Household, 15 (2), 357-382.

World Health Organization (2015). Disponible en: <https://www.afro. who.int/sites/default/files/2017-06/malawi-who-country-office2015-annual-report.pdf>

World Population Prospect 2015.

Zolowere, D.; Manda, K.; Panulo, B. y Muula, A. S. (2008). «Experiences of self-disclosure among tuberculosis patients in rural Southern Malawi». Rural and remote health, 8 (4), 1-9.

\section{Anexos}

\section{Noticias de prensa local}

\section{Maybe electricity is a luxurious product}



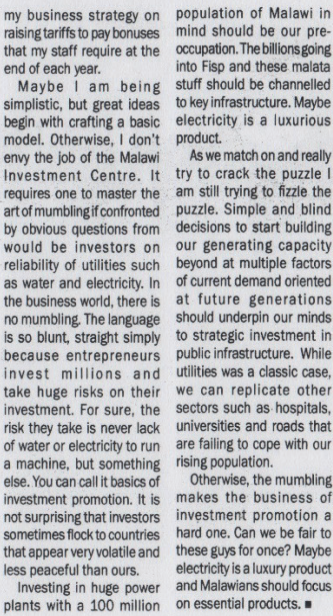

Artículo sobre los problemas que generan los cortes diarios de suministro eléctrico. 
18 OPINION

WEDNESDAY, 25 OCTOBER 201

My Consequences of bloodsucking rumours

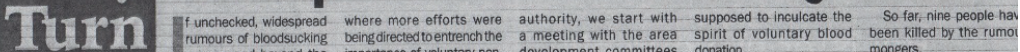

may spread beyond the importance of voluntary non- development committees donation.
mongers. affected southern parts of the remunerated blood donation. (ADC), sensitising them to With the rumoured But figures illustrate wh country. After almost 14 years voluntary blood donation. bloodsucking, the traditional we are about to face if th In fact, they have already of advocating for voluntary The meeting draws hospital authorities are now being bizarre story

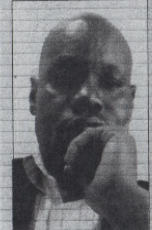

ALIEN TRENCH

KAOMBE Chirtrom Mulanje, Phalombe, City of Biantyre.

If entrenches, the country of bloodsucking arise and taboratonyeathsurvellance fear. If those peddlling these In Juty, August an threaten to erode the gains assistants and $A D C$ members unsetting numours are beating September last year, MB Talawi has made in blood headed by the traditional and killing chiefs, what more collected 6600 units of blo sonnel, in southem parts of Malaw $\begin{array}{ll}\text { should brave formultifaceted, donation. } & \text { hospital personnel, in By contrast, only arour }\end{array}$ The country MBTS staft, ADC 4600 units of whole blo - stakeholders? These have been collected in to

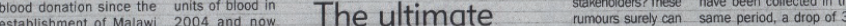
Terice in collects 60000

Voluntany bot donation sificionthe began in 2004 , starting The gain is with Blantyre as the first obvious. branch of MBTS. The critical Do we want to tasks included establishing lose such gains operational relationships with in times when, various stakeholders and strategically. collecting blood. voluntary blood Relationshipswere created donation is being with leadership from places targeted at rural of work and worship, colleges areas? and secondary schools, Nol health surveillanceassistants, We as a country traditional leaders, information cannot afford to do officers, non-governmental that because of organisations with grassroots mere rumours of

The author is Malawi Blood Transfusion Service (MBTS) public relations structures. bloodsucking. losers are take us backwards. peroent. in rural areas, In the same period, MB patients head teachers and Region this year versus 2 patrons are in the in 2016 . Who need forefront advocating Thenumber of sites visit blood motivate pupils of units of blood? to donate blood, The drop is worrisome.
sometimes citing The ultimate losers a cases whereby they patients who need bio in hospitals blood shortage at Arewe going to allowthe the hospital. the hospital. rumours erode our progre encourage pupils to The country cannot affe encourage pupis to

Forblood donationactivity to authority. Then sensitisation. The mere mention of Let's work together happen, variousstakeholders and blood collection dates "blood donation' leaves one enhance the gains population is based in the happen, variousstakeholders and blood collection dates 'blood donation' leaves one enhance the gains
rural areas and this is also take part. It depends on the are set.
wheremore bloodiscollected. area or institution.

population is based in the happen, variousstakeholders and blood collection dates 'blood donation' leaves one enhance the gains
rural areas and this is also take part. It depends on the are set.
wheremore bloodiscollected. area or institution.
These people live in the to death as a suspected voluntary blood donatio wheramo are bloodiscollected. area or institution.
whe rural areas are places When visting a traditional rural areas where we were bloodsucker.

La muerte de nueve personas en distritos cercanos a la ciudad de Blantyre desató los rumores de «vampirismo», que decretaron el estado de excepción durante algunos días en la ciudad. 


\section{Teen mother dreams bigger}

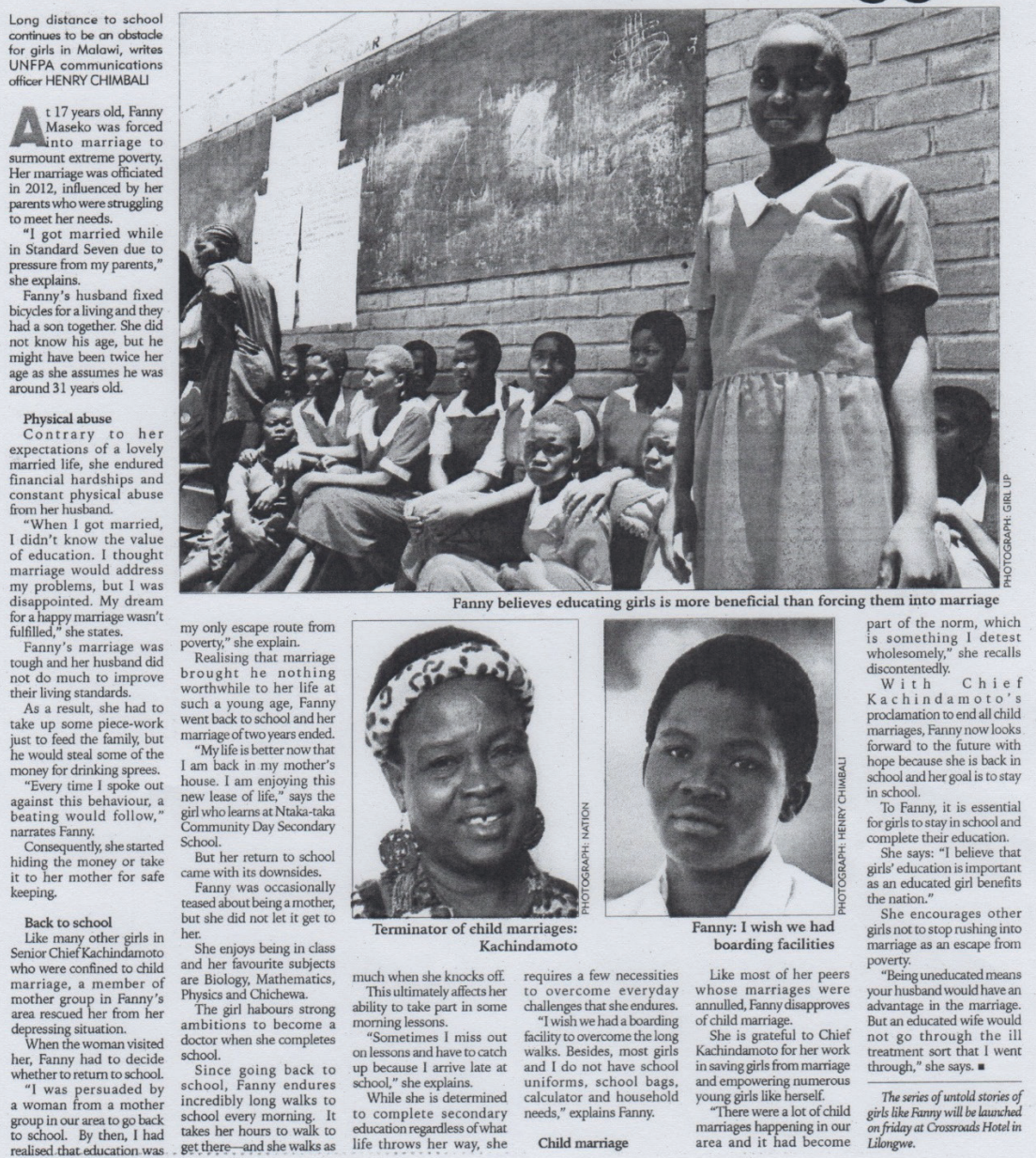

Madres adolescentes. 


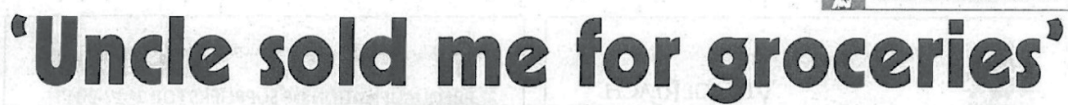

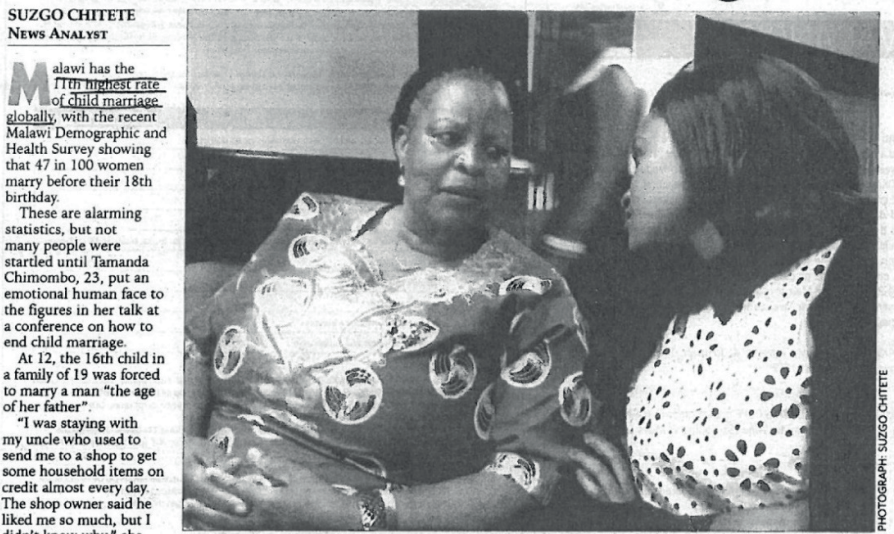
didn't know why," she

As a Standard Seven at Ligowe Primary School in Neno, Tamanda became a shopkeeper as her uncle said the businessperso needed an extra hand. "I was excited to give a hand to $\mathrm{Mr}$ Chisale. Later, my uncle told me to move to the

Chikumbu sharing a point with Tamanda at the gender policy dialogue last week

shopkeeper's home," she usually got disturbed when onlookers started married shop owner

\section{The shock} Ngoni girls are taught to respect elders. For a month, she combined household chores and shop-keeping. Tamanda says she baby. I wept and fled back shop because he could to my uncle," she recalls. "Unfortunately, he why I was running away from my husband Angrily, he disclosed offering me to marry Chisale in exchange for the items I got from the not pay back." the minor stayed with the elderly husband for three months as she waited to go into Standard 8 .

The escape shouted at me, asking when Mr Chisa and that I owed him a Guided by a wellwisher who advised he about the importance of education, Tamand terminated the polygamous marriage and reported the matter to Neno District Welfar and later convicted of marrying a mino The girl, who sought refuge in her grandmother's home and went back to school, wa scorned by her peers and adults for escaping from marnage.

The insults made me work harder in school to show them that there is a brighter future beyond marriage," she says.

A year after breaking free, Tamanda was the only student at Ligow selected to a national
institution-Blantyre

Secondary School.

Today, she holds

a diploma in human resource management. While working as signal monitoring officer the Malawi Digital Broadcasting Network is studying for a degree in is studying for a degree in at DMI University in Mangochi.

Policy dialogue

We need to reach

gut to girls to know that they are not equal to for gage, but destined or greater things. If girls are empowered, it will be difncult wo lure them Senior Chief

Chikumbu of Mulanje asks tradicional leaders forces or allows a minot fores or allows a minor to marry. She wants community leaders to take action and report with the Marriage Act and by-laws which outlaw marriages involving girls below 18.

"We are sometimes let down by the police and courts which leave some says Chikumbu

Concurring, gender activist Emma Kaliya calls for concerted efforts by organisations to avoid duplicating and concentrating interventions in one area while other localities remain unreached.

"We need to reach

out to all areas. Child marriage is an issue and marriage is an issue and
we need more advocacy to protect the rights and well-being of girls," she says.

Minister of Gender Children, Disability and Social Welfare Jean Kalilani says government will intensify the push to ensure every girl learns and achieves her potential.

"This is more the reason we have the re admission policy," she says, "Girls must go back to school after dropping out due to marriage or teen pregnancy."

According to the World Bank, only 27 percent of girls in the country enroll in secondary school. The majority are not in school and susceptible to early marriage. "

El drama de los matrimonios forzados. 


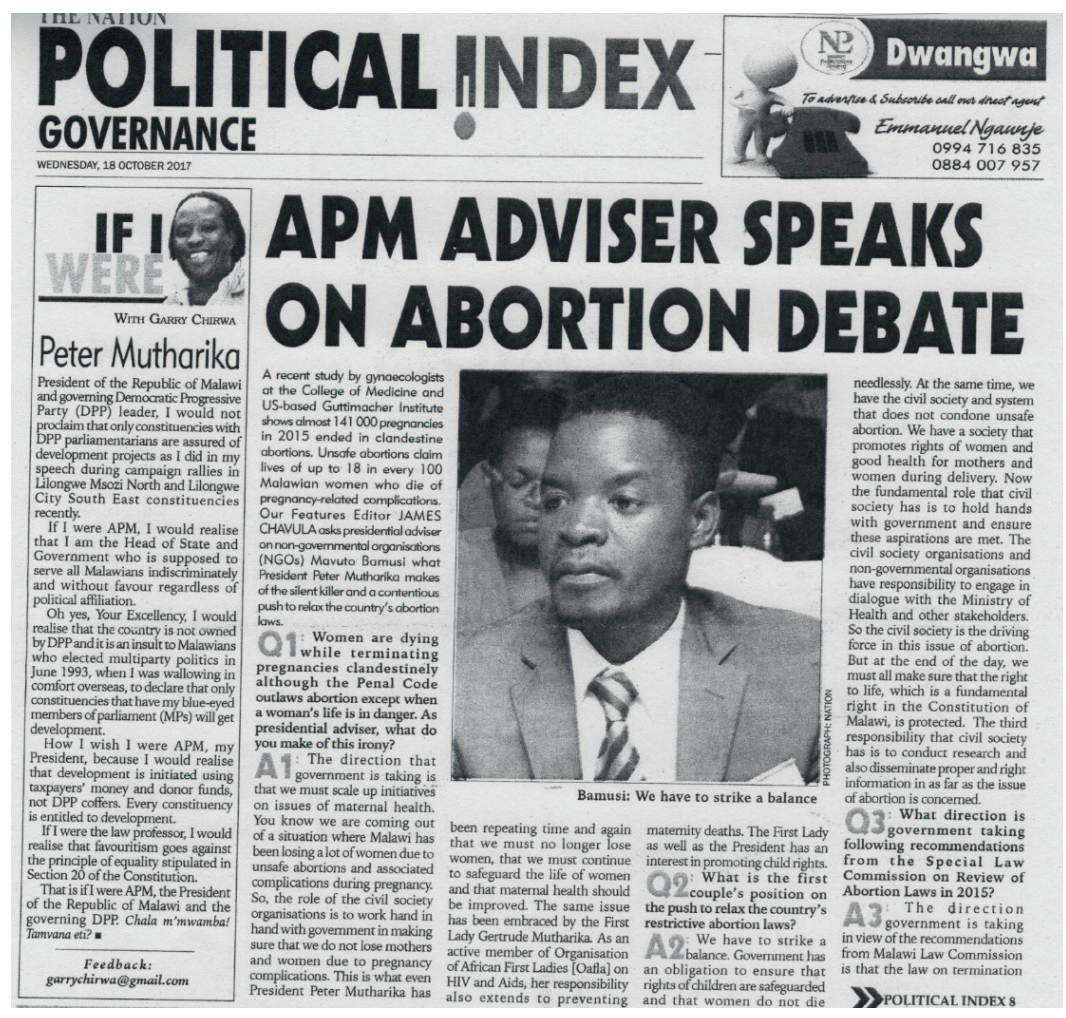

El aborto empieza a debatirse públicamente tras la denuncia de 141.000 abortos clandestinos que provocan la muerte de numerosas mujeres. 


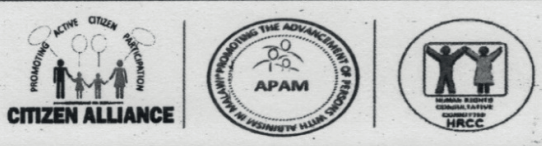

THE PLIGHT OF PERSONS WITH ALBINISM IN THE WAKE OF ATTEMPTED KILLING OF "ISRAAJ MBALAKA" AND THE UN'S DECISION TO PULL OUT OF OPERATIONAL DISTRICTS DUE TO "BLOOD SUCKERS" Allegations

Appreciating the sustenance of the founding goals of APAM i.e. to serve as a solid and durable establishment to protect and promote as well as enjoyment of fundamental rights and freedoms of their members (Persons with Albinism) and its commitment to harmonious working relationship with both State and Non-State Actors over the vears, the tripartite parthers (namely APAM, HRCC and Citzen alliance) feel duty bound to reintorce their partnership duties through this statement as a means of ensuring the enjorment of social, civil and
political rights of persons with albinism while expressing appreciation for the support received from both Public political rights of persons with albinism while expressing appreciation for the support recelv
(Government) \& Private Sector, CSOS and International Agencies in furthering our goals

It is sickening to note that just as APAM and partners were noticing progress in the curbing of violence against persons with albinism, latest reports from Ntaja reveals that attempted murder of Israjj Mbalaka on the 13th of October 2017 was foiled by Police. Reports indicate that his relative cheated him that he had found him a job at Ntaja where he went to sell him to a businessperson at the cost of Mina, $000,000.00$. The Businessman ipped Police which resulted in the arrest of the suspect. The case demonstrates the need for the country to have a continuous response strategy with various players, we lass with the recent spate of violence and lawiessness which erupted the past weeks over "biood sucking" allegations.

What's heartening and disturbing is the fact that 9 people have lost their lives on allegations that they are blood suckers yet both Police and health officials have confirmed non-existence of evidence in both the killed and those claiming to have been sucked that they indeed were blood suckers or were sucked of their blood. We note that harmful traditional practices are beginning to evolve and morph into dimensions that now include unsubstantiated cases of blood suckers. So sad is the fact that this partcular plague is now cargeting everyone and anyone living, visiting or working in the areas affected, UN personnel and health workers included. We strongly condemn lawlessness, stoning of ambulances; private vehicles
innocent people over these allegations, this cannot be allowed to continue.

APAM and its partners are compelled by these grotesque circumstances of lawlessness to call upon all lawabiding citizens to refrain and desist from taking the low in own hands before these unfounded mob justice plunges this country into more deoths of innocent and productive citizens.

It is the prayer of APAM and its partners that in the immediacy all law-abiding citizens should join hands at any cost to restore social cohesion and allow progressive realizations of sustainable social economic growth to return on course. It is important for all Malawians of goodwil to permit social services including essential be reinstated in the best interest of all people living in the affected areas.

of particular and gravest concern is the withdrawal of UN personnel from areas affected in Mulanje, Phalombe, Chiradzulu and recently Machinga. This development is worrisome and needs to urgently be revisited to ensure that the withdrawn services are restored in the best interest of the citizenry in those areas

Our strongest fears are that a delay to restore peace and tranquility in the affected areas shall mean afl the gains which have been made on the ground and interventions preventing further violence, killings, trespassing and exhumation of graves for PWA woun

On e positive note, we acknowledge the wise, courageous and dynamic leadership demonstrated by the Head of State President Professors Arthur Peter Mutharika for quickly visiting the area affected, and interacting with the victims of blood sucking to obtain the first impression of the issues while at the same time offering hope to the citizens that their leader is with them in this trying time. More so, his decision to order the Defense force presence in all areas is well recelved and necessary if we are to fight the vice.

Furthermore, APAM and its partners make recommendation to Civil Society Organizations working in the affected areas to take advantage of their reasonable acceptability to sensitize the communities on the suitability and relevance of relerral systems involving Communityosed to mob justice. It is possible that had the and process suspicions of criminais or criminal activites as opposed to mave unveiled the gross network and motivation of the blood suckers if at all we are to believe any of the killed had a hand in this vice!

By extension, APAM and its partners, would like to publicly put on record that we are forever grateful to all partners( Police, CSo, Army, Politicians, Health workers, Government and Private sector, Development partners led by the UN -just to mention a few) for demonstrating suppleness, pliability, valour and fearlessness standing with all members of the association when violence, killing of persons with albinism, trespassing and exhumation of graves of persons with albinism started, motivated by superstitions and false beliefs. So tar 21 persons with albinism have been killed in Malawi since November 2014 and that 122 cases of attacks have been recorded and support which may result in more killings and victimisations, we therefore appeal for fast tracked trial of all reported cases and ensure that suspects are brought to book for a total freedom by all

Working together, we can achieve more since Building Peace is the Responsibility of All of Us! We need Love and security"l!
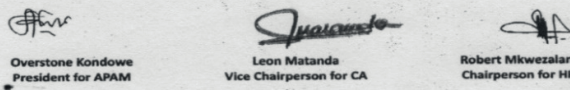

Robert Mikwezalamba

La Association of Persons with Albinism in Malawi (APAM) es una ONG que representa a las personas con albinismo en Malawi desde 1996. Denuncia en este comunicado la muerte de nueve personas, supuestamente blood-suckers, condenando también estas

prácticas. Desde 2014, esta organización ha denunciado 111 casos de abducción o asesinato de albinos en Malawi. 


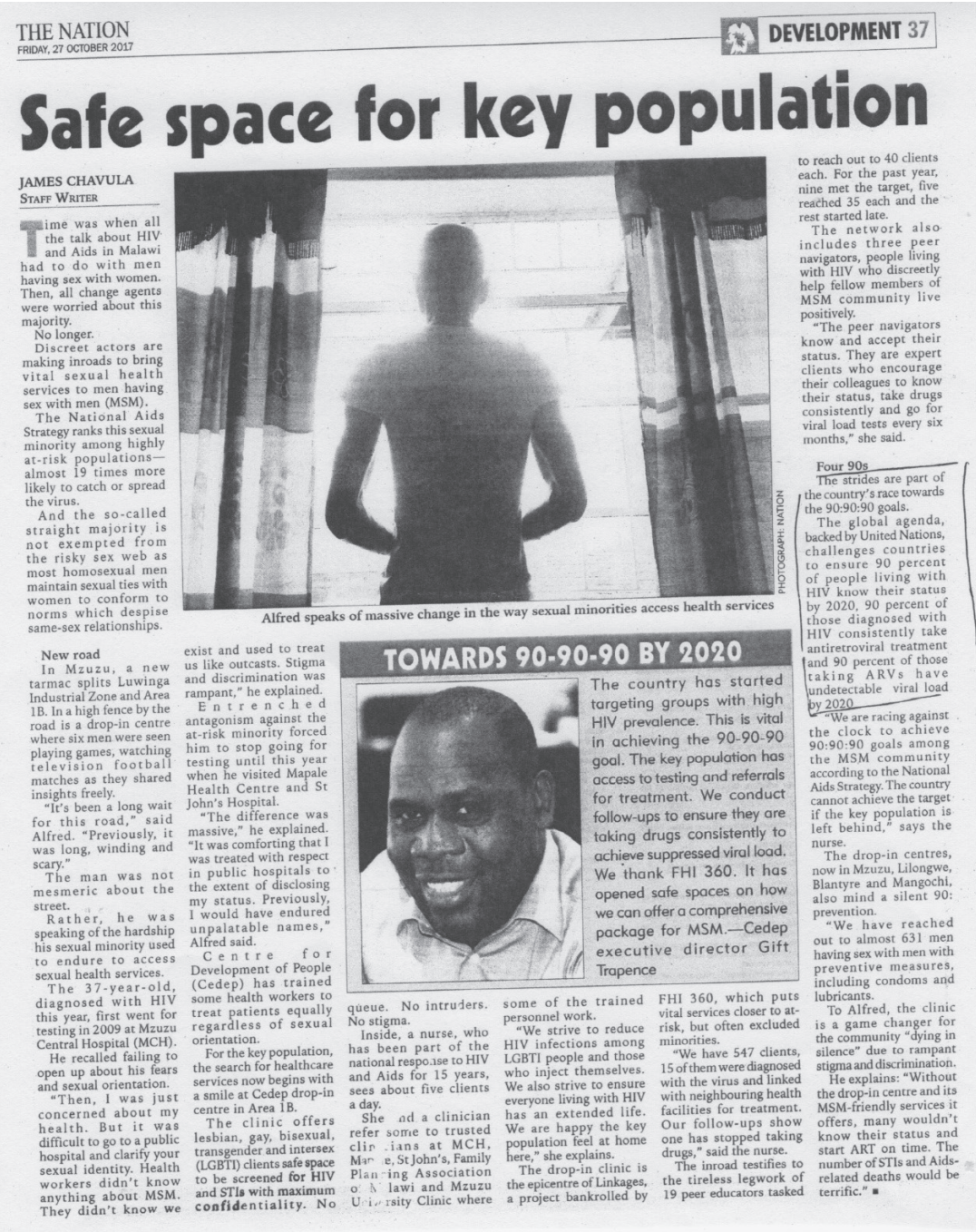

A pesar de que la homosexualidad está prohibida en el país, algunas organizaciones empiezan a concienciar a la población del problema del VIH de este colectivo. La apertura de algunos centros privados donde estas personas puedan ser orientadas y tratadas empieza a ser una tímida esperanza para ellas. 
Date :

To

Dear Sir,

\section{AN INVITATION TO ATTEND A SENSITISATION MEETING ON HOW TO PROTECT THE LIFE OF THE UNBORN BABY AND THAT OF YOUR SPOUSE}

We are pleased to invite you to accompany your spouse when coming to attend antenatal clinic services on .............................. 2016, at Likuni Mission Hospital; where we shall share with you some of the insights on how you may protect the life of the unborn baby and that of your spouse during the period of pregnancy and after the baby is born.

Your participation to this important meeting will be highly appreciated as it will help in reducing some of the avoidable complications that women faces during the time of delivery due to lack of guidance that we will share with you on this day.

Let us help in saving the life of the expectant mother and that of the unborn baby by attending this important meeting on this date.

Sincerely Yours,

\section{COORDINATOR}

SAVE THE FAMILIES FOR AFRICA



Documento facilitado por LMH. Love-letter con la que, en LMH, quieren involucrar a los maridos en el proceso de embarazo y parto de la mujer, así como facilitar el tratamiento como pareja. 


\section{Material fotográfico}
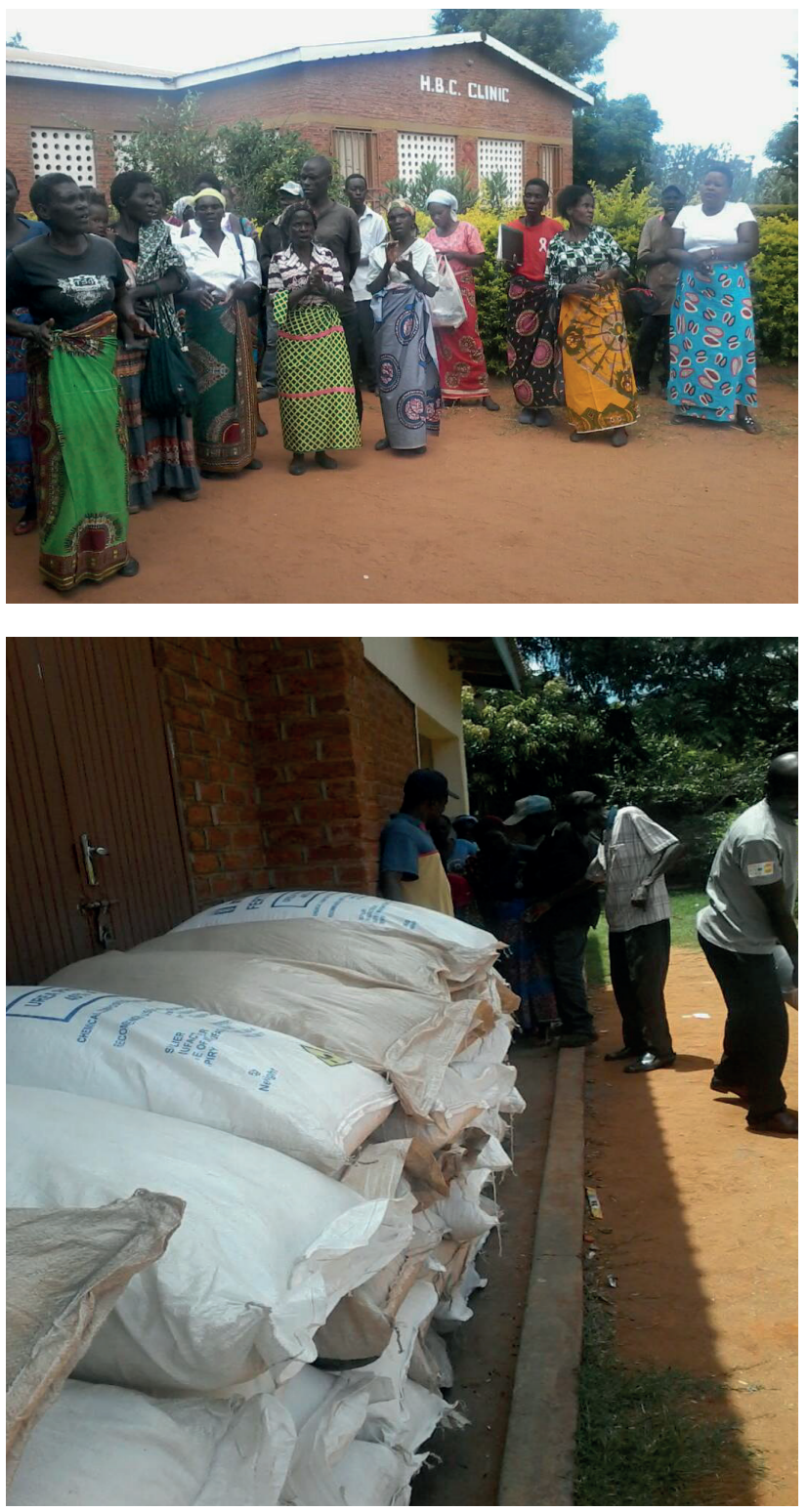

Integrantes del grupo de soporte de HBC, Área 49, esperando y celebrando la llegada de los fertilizantes. 


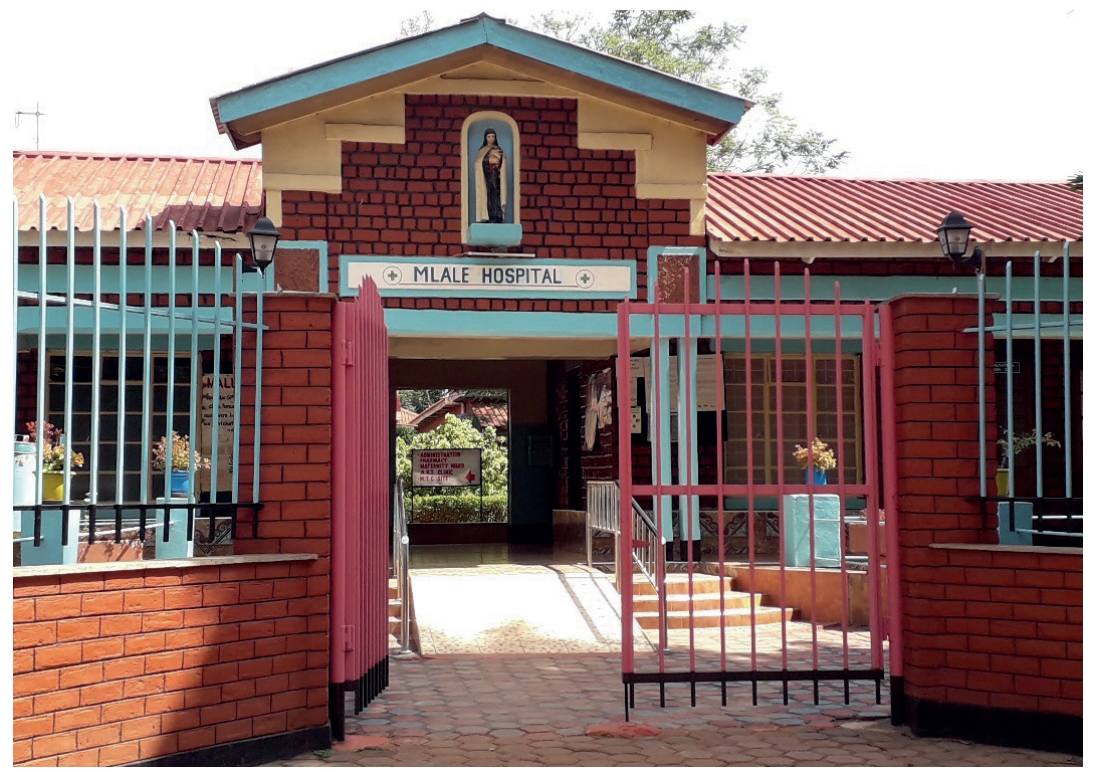

Mlale Hospital.

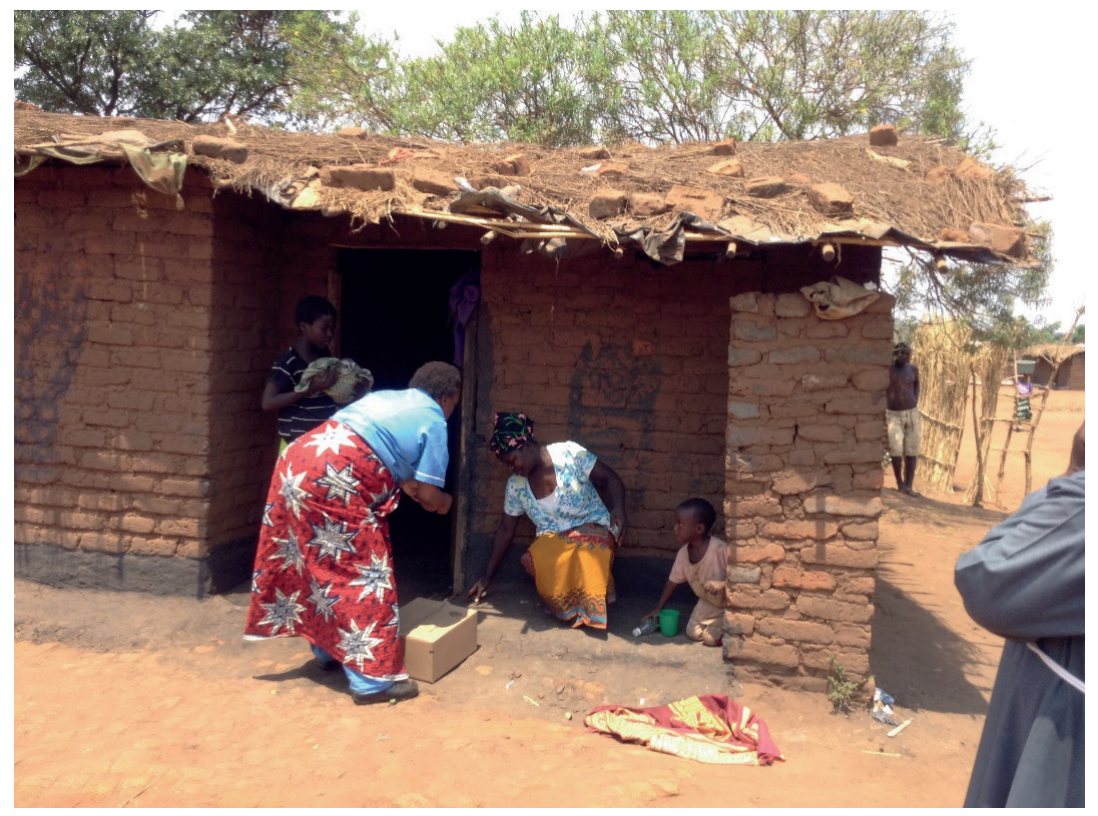

Condiciones de la vivienda de una de las pacientes. 